\title{
Telomere Length and Mental Well-Being in Elderly Men from the Netherlands and Greece
}

\author{
Nathaly Rius-Ottenheim • Joyce M. J. Houben • Daan Kromhout • \\ Anthony Kafatos - Roos C. van der Mast • Frans G. Zitman • \\ Johanna M. Geleijnse • Geja J. Hageman • Erik J. Giltay
}

Received: 23 March 2011 / Accepted: 11 August 2011/Published online: 26 August 2011

(C) The Author(s) 2011. This article is published with open access at Springerlink.com

\begin{abstract}
Telomeres, repetitive DNA sequences that promote chromosomal stability, have been related to different measures of mental well-being and self-rated health, but mainly in women during adulthood. We aimed to investigate whether accelerated telomere shortening is associated with poor mental well-being and poor self-rated health in community-dwelling elderly men. Leukocyte telomere length was measured using quantitative PCR in two different samples of 203 elderly men (mean age 78 years) from the Netherlands in 1993, and 123 elderly men (mean age 84 years) from Greece in 2000. We also obtained follow-up data in 2000 from 144 Dutch subjects, of whom 75 had paired telomere length data in 1993 and 2000. Mental well-being was conceptualized as dispositional optimism, depressive symptoms, cognitive functioning, and loneliness. Linear regression analyses were used to study the association between telomere length, measures of mental well being, and self-rated health, while
\end{abstract}

Edited by Chandra Reynolds.

N. Rius-Ottenheim $(\bowtie) \cdot$ R. C. van der Mast .

F. G. Zitman - E. J. Giltay

Department of Psychiatry, Leiden University Medical Center,

P.O. Box 9600, 2300 RC Leiden, The Netherlands

e-mail: N.Rius_Ottenheim@lumc.nl

J. M. J. Houben · G. J. Hageman

Department of Toxicology, NUTRIM School for Nutrition, Toxicology and Metabolism, Maastricht University Medical Center, Maastricht, the Netherlands

D. Kromhout · J. M. Geleijnse

Division of Human Nutrition, Wageningen University,

Wageningen, The Netherlands

A. Kafatos

Department of Preventive Medicine and Nutrition Clinic,

Medical School, University of Crete, Heraklion, Crete, Greece adjusting for potential confounders. In cross-sectional analyses, leukocyte telomere length was not associated with measures of mental well-being and self-rated health, neither in the Netherlands nor in Greece. Also, the rate of leukocyte telomere shortening (mean decrease: 0.28 kbp over 7 years) in the 75 Dutch participants with longitudinal data was not associated with changes in different measures of mental well-being and self-rated health. Thus, our results provide no support for a relationship between leukocyte telomere length and mental well-being in elderly community-dwelling men.

Keywords Telomere length - Mental well-being . Self-rated health $\cdot$ Cognitive function $\cdot$ Cohort study

\section{Introduction}

Telomeres are repetitive DNA sequences that cap chromosomal ends and play a critical role in promoting chromosomal stability (Blackburn 2001). Telomeres shorten with every cell division and, after reaching a critical length, eventually induce cellular senescence and apoptosis (Allsopp et al. 1992). Therefore, the capacity of cellular replication is modulated by processes that either accelerate or counter telomere shortening; for instance through the elongating effect of the enzyme telomerase (Greider 1996). Cellular environment also plays an important role in regulating telomere length. It has been shown that exposure to physical stressors-most convincingly shown for oxidative stress by reactive oxygen species-can hasten telomere shortening and lead to premature cell senescence (Gilley et al. 2008; Richter and Von Zglinicki 2007). Thus, telomere length reflects the cellular replicative history and the presence of many stressors at the cellular level. Besides replication timing, telomeres also participate in nuclear 
processes such as chromosome positioning in the nucleus, transcriptional repression, and heterochromatin formation (Taddei and Gasser 2004). Therefore, telomeres have been considered markers of biological aging, age-related diseases, and mortality (Benetos et al. 2001; Cawthon et al. 2003; Epel et al. 2009).

Several components of mental well-being decline with aging (Reiche et al. 2004) and are associated with an excessive activation of different stress systems. It has been hypothesized that oxidative stress through free radicals may be involved in accelerated telomere shortening in case of poor mental health states (Hovatta et al. 2010), although the detailed molecular mechanisms involved are still poorly understood. Environmental factors involved are stress, diet, smoking, substance abuse, and physical exercise (Nordfjall et al. 2008; Valdes et al. 2005). There is a rapidly growing literature on the link between poor mental well-being and telomere shortening. Several cross-sectional studies that included middle-aged (mean age ranging from 27 to 65) subjects documented a shorter mean telomere length in relation to different measures of poor mental well-being such as in case of unipolar and bipolar mood disorders (Damjanovic et al. 2007; Simon et al. 2006), dispositional pessimism (O’Donovan et al. 2009), cognitive impairment and decline (Valdes et al. 2010; Yaffe et al. 2009), Alzheimer's disease (Honig et al. 2006; Panossian et al. 2003), and childhood trauma (Kananen et al. 2010; Tyrka et al. 2009). In addition, increased psychological stress and poor self-rated mental health were also been related to shorter telomeres (Epel et al. 2004; Parks et al. 2009). Studies among elderly subjects, however, did not find a clear association between telomere length with depressive symptoms or personality traits (i.e., type D personality) among 890 older patients with chronic heart failure (Huzen et al. 2010). We are not aware of studies that prospectively studied changes in telomere length over time in relation to changes in measures of mental well-being, as prior studies had a case-control design, a cross-sectional design, or did not measure telomere length sequentially.

Although there is evidence of a relationship between telomere shortening and poor mental well-being during adulthood, it is unclear whether such an association persists in late life. We tested the hypothesis that shorter telomeres would be associated with poor well-being in data collected in the Netherlands and Greece.

\section{Methods}

Study sample

For the present study we used data from the Zutphen Elderly Study (the Netherlands) and the Cretan Elderly
Study (Greece). The Zutphen Elderly Study consisted of 553 men in 1993, of whom 390 were willing to participate (response rate $71 \%$ ), and 345 had a blood sample. However, only 203 buffy coats could be used for DNA isolation since 142 samples were not available for testing. These data were missing at random, and participants with unavailable DNA did not differ in any baseline characteristics from the participants included in the analyses. For the follow-up examination in 2000, 176 men enrolled in the study in Zutphen. Blood samples were available from 146 individuals. Because of the insufficient quality of the DNA of two of the participants, 144 men $(82 \%)$ were finally included in the present analysis. Of these 144 Dutch men who were included in the analysis in 2000, 75 men had also a blood sample available in 1993. We only had data of the Cretan sample in 2000, and not in 1993. The Cretan sample consisted of 165 men in 2000. Of these men, 152 were willing to participate (response rate 92\%) and blood samples were drawn from 129 individuals. In six men, the concentration of DNA was not sufficient to determine telomere length, yielding information on 123 Cretan men for subsequent analysis. The study was approved by local medical ethics committees.

\section{Leukocyte telomere length measurement}

Non-fasting blood samples were collected in the morning into citrate tubes. Buffy coats were obtained for subsequent DNA isolation. Samples from Zutphen were stored at $-30^{\circ} \mathrm{C}$ before transport within a few days of collection to the National Institute for Public Health and Environment (RIVM), the Netherlands. Samples from Crete were firstly stored at $-80^{\circ} \mathrm{C}$ and subsequently transported to the Netherlands on dry ice by plane. After arriving at the RIVM, all samples were stored at $-80^{\circ} \mathrm{C}$. The change in temperature storage did not affect the DNA quality, since DNA is stable at a temperature below $-20^{\circ} \mathrm{C}$ (Kohler et al. 1997). The DNA used for measurement of telomere length was extracted from a $200 \mu \mathrm{l}$ buffy coat sample by a single person, within a 4-week period, using QIAamp DNA Mini Kit (Qiagen, Venlo, the Netherlands) according to the manufacturer's protocol. The DNA was quantified using a Nanodrop instrument (Isogen Life Science, Belgium). The samples from Crete and Zutphen were processed simultaneously.

Leukocyte telomere length was determined by quantitative polymerase chain reaction (qPCR) as described by Cawthon (2002). The qPCR assay for the telomere length measurement was done within a 4-week period following the extraction of DNA. Two master mixes were prepared, one with telomere primers and one with Human $\beta$ globin (HBG) primers $(1 \times$ IQ SYBRgreen supermix from BioRad, CA, USA). To confirm reproducibility of the 
applied method, we repeated for 20 samples the leukocyte telomere length measurement by using an additional reference gene, acidic ribosomal phosphoprotein PO (36B4), $300 \mathrm{nM}$ forward primer (5'-CAGCAAGTGGGAAGGTG TAATCC- $\left.3^{\prime}\right), 500 \mathrm{nM}$ reverse primer $\left(5^{\prime}\right.$-CCCATTCTAT CATCAACGGGTACAA- $\left.3^{\prime}\right)$. The estimated $R$-square for the measurement with the extra reference gene was 0.76 $(P<0.001)$. This confirmed the reproducibility of the leukocyte telomere length measurement, with a coefficient of variation for the triplicates of the telomere reaction being $4.1 \%$ and for the reference gene was 3.0\%.

Sample DNA was pippeted into a 96-wells plate at a final concentration of $10 \mathrm{ng} / \mu \mathrm{l}$. Subsequently, $20 \mu \mathrm{l}$ of the mastermix was added and the plate was briefly centrifuged. Each sample was run in triplicates. The triplicates were located on the same qPCR-plate and for the reference gene the triplicates were located on another qPCR-plate but in the same positions. For the standard curve a reference DNA sample was diluted serially to produce three concentrations of $1.25,5$, and $10 \mathrm{ng} /$ $\mu \mathrm{l}$. In every run, negative controls (MQ + mastermix) and reference samples were included. The references were derived from two different Hela cell lines, one with relatively short telomeres (Hela S3: $5.5 \mathrm{~kb}$ ) and one with long telomeres (Hela 229: 14-15 kb). By adding reference DNA of controls to each qPCR, a standard curve could be created and the absolute telomere length of the samples could be calculated as kilobase pairs (kbp). The matched 75 samples of the Zuthpen Elderly Study were run in the same plate. Hela cell lines were kindly provided by Prof. Alexander Bürkle, University of Konstanz, Germany. The quantitative polymerase chain reaction (qPCR) was performed using a BioRad MyiQ iCycler Single Color RT-PCR detection system using $\mathrm{iQ}^{\mathrm{TM}} \mathrm{SYBR}^{\circledR}$ Green Supermix, containing iTaq Polymerase, dNTPs, SYBRGreen I, and buffers (BioRad, CA, USA).

\section{Measures of mental well-being}

Depressive symptoms were assessed in both samples in 2000 using the 15-item version of the Geriatric Depression Scale (GDS-15). The GDS-15 is a validated instrument to screen for depressive symptomatology in older people as it excludes somatic symptoms that might also be related to physical illnesses (Yesavage et al. 1982). The GDS-15 score ranges from 0 to 15 points. Depressive symptoms were additionally assessed in 1993 and 2000, only in Zutphen (The Netherlands), using the Dutch translation of the Zung self-rating depression scale (Zung SDS). The index score of the Zung SDS (i.e., [sumscore/80] $\times 100$ ) varies from 25 to 100 points (Kitchell et al. 1982; Okimoto et al. 1982; Zung 1965).

Dispositional optimism was assessed in all participants of both samples in 1993 and 2000 using a four-item questionnaire (Giltay et al. 2006) consisting of the following statements- "I still expect much from life", "I do not look forward to what lies ahead for me in the years to come", "My days seem to be passing by slowly", and "I am still full of plans" (our translations). Within the four score items, two negatively stated items required reversed coding. The additional answer category "do not know" was also coded as the midpoint (score 1). The optimism questionnaire score ranges from 0 to 8 points, higher scores being indicative of higher optimism levels. For the computation of the optimism score only one missing item per subject was allowed, being subsequently imputed with the mean of the remaining three items. Internal consistency was of moderate strength (Cronbach's alpha was 0.63 in 2000).

Global cognitive function was tested in 1993 and 2000 only in the Zutphen sample (The Netherlands). The assessment was performed by a trained nurse or interviewer using the 30-point Mini-Mental State Examination test (MMSE) (Folstein et al. 1975). This occurred in a protocolized way in which care was taken to prevent other persons (e.g., wife) to assist the participant during the MMSE testing.

Feelings of loneliness were assessed in both samples in 1993 and 2000 using the Loneliness Scale of De Jong Gierveld. The loneliness scale comprises 11 items, with responses coding on a $0-5$ Likert scale. A sample questionnaire item is "I find my circle of acquaintances too limited". The loneliness score ranges from 0 to 11 points (Scharf and De Jong-Gierveld 2008). This scale has been shown to have good internal consistency (Cronbach's alpha 0.82) (De Jong-Gierveld and Kamphuis 1985).

Participants were asked to report their health status through a single-item question: "How would you describe your current health status". There were five possible answers to this question, ranging from excellent to bad health.

All questionnaires were translated to the participant's native language (Dutch or Greek).

Possible confounders

Sociodemographic, lifestyle, and morbidity parameters were obtained using protocolized structured questionnaires (Keys et al. 1966). Living arrangement was dichotomized as living alone or with others; smoking status as smokers and non smokers; and alcohol consumption as users and non-users. Body mass index (BMI) was calculated by dividing body weight $(\mathrm{kg})$ by the squared height $(\mathrm{m})$ of the participant. Physical activity was assessed with a validated questionnaire designed for retired men to calculate the total minutes per week spent in different physical activities (i.e., walking, cycling, gardening, odd jobs, sports, hobbies, and work) (Caspersen et al. 1991). Presence of chronic diseases, defined as having either cardiovascular diseases (i.e., stroke, myocardial infarction, or heart failure), diabetes 
mellitus or cancer, was determined by a survey questionnaire and confirmed with hospital discharge data and written information from the general practitioner.

\section{Statistical analysis}

Baseline and follow-up telomere length were normally distributed. As MMSE scores were negatively skewed (due to the ceiling effect of the maximum score of 30), 32 minus the score was $\log$-transformed and inverted to normalize the distribution. Physical activity was positively skewed and logarithmically transformed before the analyses. Geometric means are presented with tenth and 90th percentiles [P10; P90]. Other data are presented as numbers and percentages for categorical variables, and means \pm standard deviations, or medians with interquartile ranges for continuous variables (when appropriate). The decline in telomere length over time in the Zutphen sample was tested by $t$-test for paired samples.

Linear regression was used to analyze the cross-sectional and longitudinal associations of leukocyte telomere length with self-rated health, and measures of mental wellbeing (i.e., dispositional optimism, depressive symptoms, cognitive function, and loneliness). Multivariate models were applied to adjust for the effect of potential confounders. Firstly, we tested the association between leukocyte telomere length and mental well-being or self-rated health in a crude model. Subsequently, we adjusted for age. Finally, we additionally adjusted for the following covariates: living arrangement, smoking status, alcohol consumption, physical activity, chronic diseases, and BMI. Sensitivity analyses were conducted after excluding subjects with a history of cardiovascular disease, diabetes mellitus, or cancer.

An additional linear regression analysis was used to assess associations between changes in leukocyte telomere length and changes in measures of poor mental well-being and self-rated health. Again, multivariate models as described above were applied to adjust for the effect of potential baseline confounders.

All $P$-values are two-tailed and considered statistically significant at the level of $P<0.05$. Data analyses were performed using SPSS for Windows, version 17.0 (Chicago, IL).

\section{Results}

Sociodemographic and clinical characteristics of both samples are summarized in Table 1. The mean age of men from Zutphen in 1993 was 78 years (range 72-91); whereas in 2000, the mean age of men from both Crete and Zutphen was 84 years old (range 79-98). In 2000, Cretan elderly men had longer telomeres (mean telomere length $5.0 \mathrm{kbp}$ ) than elderly men from Zutphen (mean telomere length $4.8 \mathrm{kbp}$; $P<0.001$ ). Regarding mental well-being, Cretan elderly men were less optimistic and showed more depressive symptoms than elderly men from Zutphen $(P<0.001)$. Although more Cretan elderly men rated their health status as poor, they were less likely to have chronic diseases compared to elderly men from Zutphen $(P<0.001)$. Finally, Cretan elderly men reported more physical activity than elderly men from Zutphen $(P<0.001)$.

Table 2 shows the results from the linear regression analyses for the elderly men from Zutphen and Crete. We found no statistically significant associations between leukocyte telomere length with self-rated health or any measure of mental well-being. In an additional analysis in men from Zutphen in 1993, we found no differences in telomere length among groups categorized according to quartiles of the MMSE (mean TL of 4.99 vs. 5.08 in lower versus upper quartile with $\mathrm{MMSE} \leq 23$ and $\geq 29$ points; $P=0.42$ ). Sensitivity analyses in elderly men free from chronic diseases confirmed the absence of any tendency towards an association between leukocyte telomere length and selfrated health or mental well-being (data not shown). Multivariate adjustments for potential confounding factors did not alter these results (i.e., Models 1 and 2).

Additional analysis of the paired DNA samples from 75 Dutch participants with data in 1993 and in 2000 showed that the mean telomere length in 1993 was $5.03 \mathrm{kbp}$, whereas the mean telomere length in 2000 was $4.76 \mathrm{kbp}$. The mean decline in leukocyte telomere length during 7 years of follow-up was 40.2 bp per year (95\% confidence interval $[\mathrm{CI}]: \quad 26.9-53.5 ; \quad P<0.001)$, as previously described (Houben et al. 2011). Although most individuals showed a decrease in telomere length, for 12 participants $(16 \%)$ we found an increase. Pearson's correlation coefficient showed a moderately strong relationship between telomere length in 1993 and 2000 in 75 men $(r=0.51$; $P<0.001)$. Results from the linear regression analysis showed no association between absolute changes in leukocyte telomere length and absolute changes in any measure of mental well-being or self-rated health over seven years of follow-up (Table 3). When we used relative changes of telomere length (TL in 2000 minus TL in 1993 divided by TL in 1993) instead of absolute changes (TL in 2000 minus TL in 1993) similar results were found.

\section{Discussion}

The current study examined the association between telomere length, mental well-being, and self-rated health in two samples of elderly men (over 70 years old) from two different European countries. In contrast to previous studies among younger adults (Simon et al. 2006; O’Donovan 
Table 1 Baseline characteristics of elderly men from Zutphen (The Netherlands) in 1993 and 2000 and Crete (Greece) in 2000

\begin{tabular}{|c|c|c|c|}
\hline \multirow[t]{2}{*}{ Variables } & \multicolumn{2}{|l|}{ Zutphen } & \multirow{2}{*}{$\begin{array}{l}\text { Crete } \\
2000\end{array}$} \\
\hline & 1993 & 2000 & \\
\hline Number of participants & 203 & 144 & 123 \\
\hline Age (years), mean (range) & $77.6(72.0-91.0)$ & $84.1(79.5-98.2)$ & $84.1(79.2-93.4)$ \\
\hline Telomere length, mean \pm SD & $5.0 \pm 0.5$ & $4.8 \pm 0.3$ & $5.0 \pm 0.5$ \\
\hline GDS score, median (IQR) & - & $2(1-4)$ & $3(1-7)$ \\
\hline Zung score, median (IQR) & $42.5(26.3-66.3)$ & $46.3(38.8-50.0)$ & - \\
\hline Dispositional optimism, median (IQR) & $6(4-7)$ & $5(4-6)$ & $4(2-6)$ \\
\hline MMSE, median (IQR) & $27(25-28)$ & $28(26-29)$ & - \\
\hline Loneliness, median (IQR) & $1(0-3)$ & $2(0-5)$ & $3(1-5)$ \\
\hline Living alone, $n(\%)$ & $45(22.3 \%)$ & $56(38.9 \%)$ & $23(19.8 \%)$ \\
\hline Current smoking, $n(\%)$ & $55(29.1 \%)$ & $14(9.7 \%)$ & $11(8.9 \%)$ \\
\hline Alcohol users, $n(\%)$ & $141(76.2 \%)$ & $110(76.4 \%)$ & $66(55.5 \%)$ \\
\hline Body Mass Index, mean \pm SD & $25.6 \pm 2.6$ & $25.6 \pm 3.7$ & $24.9 \pm 4.2$ \\
\hline Physical activity (min/week), median (P10, P90) & $513(125 ; 1369)$ & $210(0 ; 835)$ & $397(0 ; 1440)$ \\
\hline Chronic diseases $^{\mathrm{a}}, n(\%)$ & $59(29.1 \%)$ & $70(48.6 \%)$ & $29(23.6 \%)$ \\
\hline \multicolumn{4}{|l|}{ Self-rated health, $n(\%)$} \\
\hline Excellent & $22(10.9 \%)$ & $7(4.9 \%)$ & $9(7.6 \%)$ \\
\hline Very good & $93(46.0 \%)$ & $19(13.3 \%)$ & $13(11.0 \%)$ \\
\hline Good & $74(36.6 \%)$ & $86(60.1 \%)$ & $34(28.8 \%)$ \\
\hline Poor & $10(5.0 \%)$ & $29(20.3 \%)$ & $39(33.1 \%)$ \\
\hline Bed & $3(1.5 \%)$ & $2(1.4 \%)$ & $23(19.5 \%)$ \\
\hline
\end{tabular}

Data are presented as $n(\%)$, mean $( \pm \mathrm{SD})$, or median $(\mathrm{IQR})$ when appropriate

${ }^{a}$ Chronic disease was defined as having prevalent cardiovascular disease (i.e., myocardial infarction, stroke, heart failure), cancer, or diabetes mellitus

et al. 2009; Panossian et al. 2003; Honig et al. 2006; Tyrka et al. 2009; Epel et al. 2004), our results revealed no crosssectional associations between leukocyte telomere length and measures of mental well-being or self-rated health, neither in the Netherlands nor in Greece. Furthermore, the longitudinal analysis of data from 75 men with measurements in 1993 and 2000 showed neither an association between the telomere shortening rate and changes in mental well-being or self-rated health.

Among the strengths of the present study is the analysis of a wide range of mental well-being variables in relation to telomere length. The longitudinal study design allowed us to identify the determinants of leukocyte telomere length change in a relatively large cohort of community-dwelling elderly subjects. Furthermore, we used the validated qPCR technique including shorter and longer sized standard samples to assess telomere length instead of the more timeconsuming southern blot (Cawthon 2002). Also noteworthy is the international design of this study. Our results were consistent in two different population-based samples of different origin and advanced age. Although we did not find statistically significant associations between telomere length and mental wellbeing, our findings suggest that the rate of telomere shortening varied across countries. The observed longer telomeres in Cretan men compared to men from Zutphen may partly be explained by different lifestyles. It is well-known that inhabitants from Mediterranean countries usually engage in healthier lifestyles than people from Northern European countries (Trichopoulou and Lagiou 1997). In our study, participants from Crete spent more time in physical activities than participants from Zutphen. Furthermore, it is possible that the Mediterranean diet (more habitual in Crete) incorporates more antioxidants that may buffer telomere shortening through reduction of oxidative stress (Dai et al. 2008; Buijsse et al. 2007). However, several limitations should be considered in the interpretation of our results. First, the elderly men had all survived until old age, meaning that they were aging relatively well. Given that cell aging processes are considered to be related to life expectancy, it is possible that the advanced age of our sample hampered the detection of a relationship between telomere length and markers of mental well-being. A second explanation may be that our study was only composed of men, which limits the generalization of our results to women, while many of the previous studies with positive findings included only women (O'Donovan et al. 2009; Valdes et al. 2010; Epel et al. 2004; Parks et al. 2009), a majority of women (Tyrka 


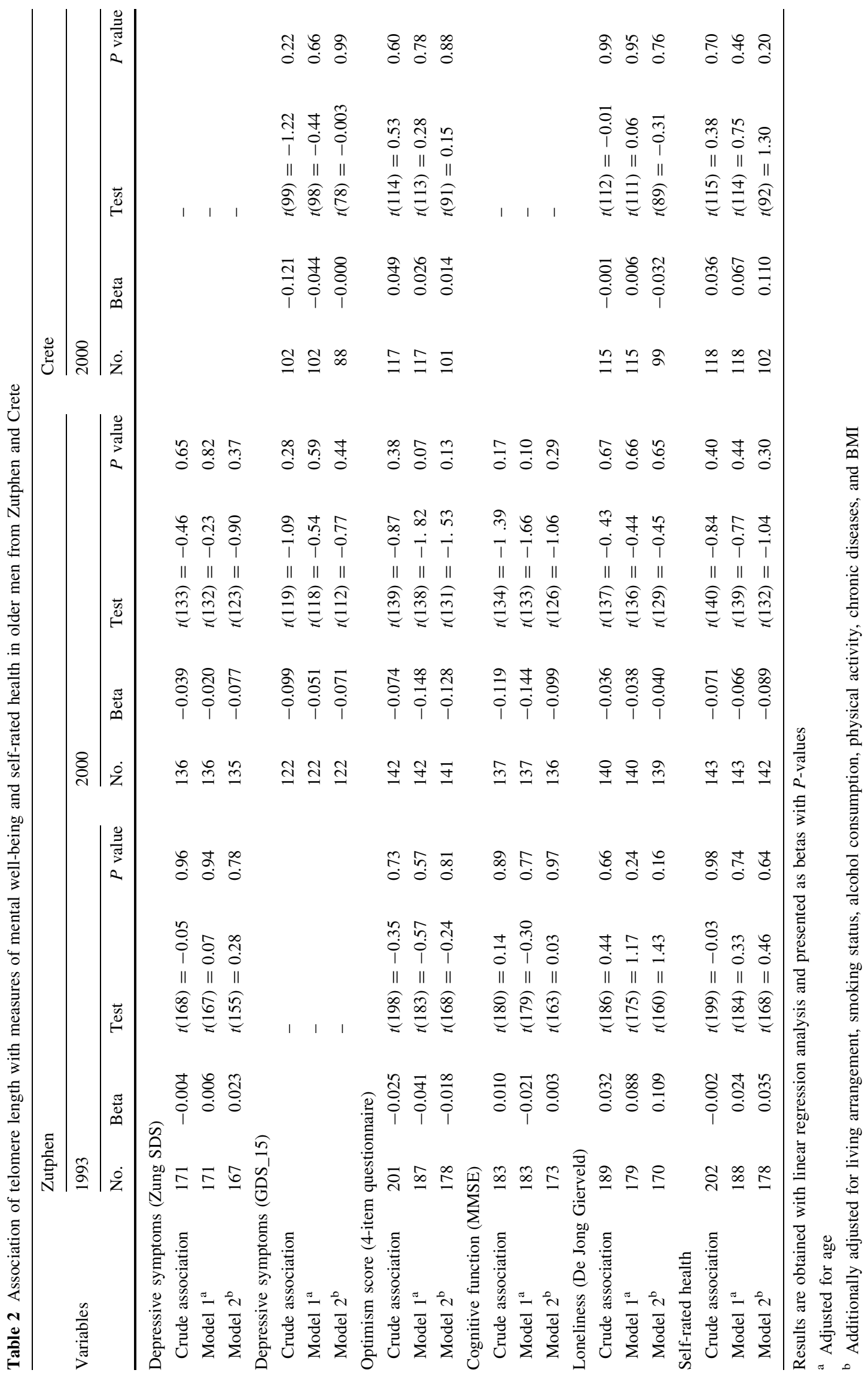


Table 3 Associatons between changes in mental well-being and selfrated heath and changes in telomere length in 75 older men from Zutphen from 1993 till 2000

Results are obtained with linear regression analysis and presented as betas with $P$-values

${ }^{a}$ Adjusted for age

b Additionally adjusted for living arrangement, smoking status, alcohol consumption, physical activity, chronic diseases, and BMI

\begin{tabular}{|c|c|c|c|}
\hline \multirow[b]{2}{*}{ Variables } & \multicolumn{3}{|c|}{$\Delta$ Telomere length } \\
\hline & Beta & Test & $P$ value \\
\hline \multicolumn{4}{|c|}{$\Delta$ Depressive symptoms (Zung SDS) } \\
\hline Crude association & -0.061 & $t(57)=-0.47$ & 0.64 \\
\hline Model $1^{\mathrm{a}}$ & -0.058 & $t(56)=-0.45$ & 0.66 \\
\hline Model $2^{\mathrm{b}}$ & -0.006 & $t(48)=-0.05$ & 0.96 \\
\hline \multicolumn{4}{|c|}{$\Delta$ Optimism score (4-item questionnaire) } \\
\hline Crude association & -0.013 & $t(71)=-0.11$ & 0.92 \\
\hline Model $1^{\mathrm{a}}$ & -0.008 & $t(68)=-0.07$ & 0.95 \\
\hline Model $2^{\mathrm{b}}$ & 0.017 & $t(59)=0.14$ & 0.89 \\
\hline \multicolumn{4}{|c|}{$\Delta$ Cognitive function (MMSE) } \\
\hline Crude association & 0.084 & $t(64)=0.68$ & 0.50 \\
\hline Model $1^{\mathrm{a}}$ & 0.092 & $t(63)=0.75$ & 0.46 \\
\hline Model $2^{\mathrm{b}}$ & 0.074 & $t(54)=0.55$ & 0.58 \\
\hline \multicolumn{4}{|c|}{$\Delta$ Loneliness (De Jong Gierveld) } \\
\hline Crude association & 0.060 & $t(66)=0.49$ & 0.62 \\
\hline Model $1^{\mathrm{a}}$ & 0.070 & $t(63)=0.56$ & 0.58 \\
\hline Model $2^{\mathrm{b}}$ & 0.106 & $t(54)=0.80$ & 0.43 \\
\hline \multicolumn{4}{|l|}{$\Delta$ Self-rated health } \\
\hline Crude association & 0.022 & $t(70)=0.18$ & 0.86 \\
\hline Model $1^{\mathrm{a}}$ & 0.033 & $t(67)=0.27$ & 0.79 \\
\hline Model $2^{\mathrm{b}}$ & 0.122 & $t(58)=0.96$ & 0.34 \\
\hline
\end{tabular}

et al. 2009; Kananen et al. 2010; Damjanovic et al. 2007), or about 50\% women (Simon et al. 2006; Yaffe et al. 2009). Third, associations may exist in clinical samples with neuropsychiatric diseases rather than epidemiological samples from the general population. Fourth, methodological error likely played a minor role, because the measurement method was rigorously tested and calibrated, and both telomere length measurements were in line with previously reported mean telomere length in this age range (Slagboom et al. 1994). Yet, a limitation of our study was that telomere length was assessed in stored buffy coats, whereas it should preferably be measured in peripheral blood mononuclear cells (PBMCs) obtained from fresh buffy coats (Choi et al. 2008). Moreover, the 4-item optimism questionnaire has not been validated yet and we relied on self-report measures rather than semi-structured psychiatric interviews for mental-wellbeing measures (except for the MMSE). Another limitation would be that we did not measure telomerase activity. Finally, though our sample was relatively large compared to most of the earlier studies among older subjects, it is possible that type II error has arisen and hampered the detection of positive associations. Therefore, future studies in larger samples are needed to confirm our results.

Although our findings contrast with several previously reports, our findings are in line with a study among 890 patients with chronic heart failure $(61 \%$ male, with a mean age of 73 years), which found no association between telomere length and self-reported depressive symptoms or the type D personality trait (Huzen et al. 2010). Although a relationship seems to exist during adulthood, leukocyte telomere length may no longer be related to mental wellbeing in the oldest old subjects. There is also evidence that there is less telomere length variation in the healthy elderly subjects versus younger subjects (Halaschek-Wiener et al. 2008). Moreover, there may be a higher degree of telomere length instability in older subjects, which may also explain our null findings (Harris et al. 2006; Martin-Ruiz et al. 2005). The instability of telomere length in the old age is thought to derive from an altered function of the enzyme telomerase, but this hypothesis is yet to be confirmed. In the current Dutch cohort, we previously found that telomere length did not predict mortality at old age (Houben et al. 2011), similar to the subgroup of participants aged 75 years or older, in which telomere length was also no longer a significant predictor of mortality (Cawthon et al. 2003).

Mental well-being is known to deteriorate in old age. Dispositional optimism declines with age (Giltay et al. 2006), whereas self-reported depressive symptoms (Barefoot et al. 2001; Davey et al. 2004), cognitive function (Schonknecht et al. 2005), and loneliness (CohenMansfield et al. 2009) increase over time. It has been suggested that psychosocial or biological stressors might act as mediators between telomere shortening and measures of poor mental well-being or self-rated health, for 
instance through increased oxidative stress on cellular level (Hovatta et al. 2010; Tyrka et al. 2009). Although some studies did find evidence of an association between higher levels of oxidative stress and measures of poor mental well-being including dementia and depression (Simon et al. 2006; Damjanovic et al. 2007; Valdes et al. 2010; Yaffe et al. 2009; Panossian et al. 2003), the mechanism underlying the transduction of such stressors to oxidative stress on cellular level remains to be further elucidated.

In summary, our results provide no support for the relationship between leukocyte telomere length and mental well-being or self-rated health in elderly men.

Acknowledgments The Zutphen Elderly Study was supported by grants from The Netherlands Prevention Foundation (Praeventiefonds). Part of this study was funded by a grant from The Netherlands Brain Foundation (Hersenstichting, Nederland, grant number 15F07(2)0.24). The survey on Crete was financially supported by Danone. The funder had no role in the design, analysis, conduct or reporting of the study.

Conflict of interest The authors report no potential conflicts of interest.

Open Access This article is distributed under the terms of the Creative Commons Attribution Noncommercial License which permits any noncommercial use, distribution, and reproduction in any medium, provided the original author(s) and source are credited.

\section{References}

Allsopp R, Vaziri H, Patterson C, Goldstein S, Younglai E, Futcher A, Greider C, Harley C (1992) Telomere length predicts replicative capacity of human fibroblasts. Proc Natl Acad Sci USA 89(21): 10114-10118

Barefoot J, Mortensen E, Helms M, Avlund K, Schroll M (2001) A longitudinal study of gender differences in depressive symptoms from age 50 to 80. Psychol Aging 16(2):342-345

Benetos A, Okuda K, Lajemi M, Kimura M, Thomas F, Skurnick J, Labat C, Bean K, Aviv A (2001) Telomere length as an indicator of biological aging: The gender effect and relation with pulse pressure and pulse wave velocity. Hypertension 37(2):381-385

Blackburn E (2001) Switching and signaling at the telomere. Cell 106(6):661-673

Buijsse B, Feskens E, Moschandreas J, Jansen E, Jacobs DJ, Kafatos A, Kok F, Kromhout D (2007) Oxidative stress, and iron and antioxidant status in elderly men: differences between the Mediterranean south (Crete) and northern Europe (Zutphen). Eur J Cardiovasc Prev Rehabil 14(4):495-500

Caspersen C, Bloemberg B, Saris W, Merritt R, Kromhout D (1991) The prevalence of selected physical activities, their relation with coronary heart disease risk factors in elderly men: the Zutphen Study, 1985. Am J Epidemiol 133(11):1078-1092

Cawthon R (2002) Telomere measurement by quantitative PCR. Nucl Acids Res 30(10):e47

Cawthon R, Smith K, O’Brien E, Sivatchenko A, Kerber R (2003) Association between telomere length in blood and mortality in people aged 60 years or older. Lancet 361(9355):393-395

Choi J, Fauce S, Effros R (2008) Reduced telomerase activity in human $\mathrm{T}$ lymphocytes exposed to cortisol. Brain Behav Immun 22(4):600-605
Cohen-Mansfield J, Shmotkin D, Goldberg S (2009) Loneliness in old age: longitudinal changes and their determinants in an Israeli sample. Int Psychogeriatr 21(6):1160-1170

Dai J, Jones D, Goldberg J, Ziegler T, Bostick R, Wilson P, Manatunga A, Shallenberger L, Jones L, Vaccarino V (2008) Association between adherence to the Mediterranean diet and oxidative stress. Am J Clin Nutr 88(5):1364-1370

Damjanovic A, Yang Y, Glaser R, Kiecolt-Glaser J, Nguyen H, Laskowski B, Zou Y, Beversdorf D, Weng N (2007) Accelerated telomere erosion is associated with a declining immune function of caregivers of Alzheimer's disease patients. J Immunol 179(6): 4249-4254

Davey A, Halverson CJ, Zonderman A, Costa PJ (2004) Change in depressive symptoms in the Baltimore longitudinal study of aging. J Gerontol B Psychol Sci Soc Sci 59(6):270-277

De Jong-Gierveld J, Kamphuis F (1985) The development of a raschtype loneliness scale. Appl Psychol Meas 9:289-299

Epel E, Blackburn E, Lin J, Dhabhar F, Adler N, Morrow J, Cawthon R (2004) Accelerated telomere shortening in response to life stress. Proc Natl Acad Sci USA 101(49):17312-17315

Epel E, Stein Merkin S, Cawthon R, Blackburn E, Adler N, Pletcher M, Seeman T (2009) The rate of leukocyte telomere shortening predicts mortality from cardiovascular disease in elderly men. Aging 1(1):81-88

Folstein M, Folstein S, McHugh P (1975) Mini-mental state. A practical method for grading the cognitive state of patients for the clinician. J Psychiatr Res 12(3):189-198

Gilley D, Herbert B, Huda N, Tanaka H, Reed T (2008) Factors impacting human telomere homeostasis and age-related disease. Mech Ageing Dev 129(1-2):27-34

Giltay E, Kamphuis M, Kalmijn S, Zitman F, Kromhout D (2006) Dispositional optimism and the risk of cardiovascular death: the Zutphen Elderly Study. Arch Intern Med 166(4):431-436

Greider C (1996) Telomere length regulation. Annu Rev Biochem 65:337-365

Halaschek-Wiener J, Vulto I, Fornika D, Collins J, Connors J, Le N, Lansdorp P, Brooks-Wilson A (2008) Reduced telomere length variation in healthy oldest old. Mech Ageing Dev 129(11):638-641

Harris SE, Deary IJ, MacIntyre A, Lamb KJ, Radhakrishnan K, Starr JM, Whalley LJ, Shiels PG (2006) The association between telomere length, physical health, cognitive ageing, and mortality in non-demented older people. Neurosci Lett 406(3):260-264

Honig L, Schupf N, Lee J, Tang M, Mayeux R (2006) Shorter telomeres are associated with mortality in those with APOE epsilon4 and dementia. Ann Neurol 60(2):181-187

Houben J, Giltay E, Rius-Ottenheim N, Hageman G, Kromhout D (2011) Telomere length and mortality in elderly men: the Zutphen Elderly Study. J Gerontol A Biol Sci Med Sci 66(1):38-44

Hovatta I, Juhila J, Donner J (2010) Oxidative stress in anxiety and comorbid disorders. Neurosci Res 68(4):261-275

Huzen J, van der Harst P, de Boer R, Lesman-Leegte I, Voors A, van Gilst W, Samani N, Jaarsma T, van Veldhuisen D (2010) Telomere length and psychological well-being in patients with chronic heart failure. Age Ageing 39(2):223-227

Kananen L, Surakka I, Pirkola S, Suvisaari J, Lonnqvist J, Peltonen L, Ripatti S, Hovatta I (2010) Childhood adversities are associated with shorter telomere length at adult age both in individuals with an anxiety disorder and controls. PLoS One 5(5):e10826

Keys A, Aravanis C, Blackburn H, Van Buchem F, Buzina R, Djordjevic B, Dontas A, Fidanza F, Karvonen M, Kimura N, Lekos D, Monti M, Puddu V, Taylor H (1966) Epidemiological studies related to coronary heart disease: characteristics of men aged 40-59 in seven countries. Acta Med Scand Suppl 460:1-392

Kitchell M, Barnes R, Veith R, Okimoto J, Raskind M (1982) Screening for depression in hospitalized geriatric medical patients. J Am Geriatr Soc 30(3):174-177 
Kohler T, Rost A, Remke H (1997) Calibration and storage of DNA competitors used for contamination-protected competitive PCR. Biotechniques 23(4):722-726

Martin-Ruiz C, Gussekloo J, van HD, von ZT, Westendorp R (2005) Telomere length in white blood cells is not associated with morbidity or mortality in the oldest old: a population-based study. Aging Cell 4(6):287-290

Nordfjall K, Eliasson M, Stegmayr B, Lundin S, Roos G, Nilsson P (2008) Increased abdominal obesity, adverse psychosocial factors and shorter telomere length in subjects reporting early ageing; the MONICA Northern Sweden Study. Scand J Public Health 36(7):744-752

O'Donovan A, Lin J, Dhabhar F, Wolkowitz O, Tillie J, Blackburn E, Epel E (2009) Pessimism correlates with leukocyte telomere shortness and elevated interleukin-6 in post-menopausal women. Brain Behav Immun 23(4):446-449

Okimoto J, Barnes R, Veith R, Raskind M, Inui T, Carter W (1982) Screening for depression in geriatric medical patients. Am J Psychiatry 139(6):799-802

Panossian L, Porter V, Valenzuela H, Zhu X, Reback E, Masterman D, Cummings J, Effros R (2003) Telomere shortening in T cells correlates with Alzheimer's disease status. Neurobiol Aging 24(1):77-84

Parks C, Miller D, McCanlies E, Cawthon R, Andrew M, DeRoo L, Sandler D (2009) Telomere length, current perceived stress, and urinary stress hormones in women. Cancer Epidemiol Biomarkers Prev 18(2):551-560

Reiche E, Nunes S, Morimoto H (2004) Stress, depression, the immune system, and cancer. Lancet Oncol 5(10):617-625

Richter T, Von Zglinicki T (2007) A continuous correlation between oxidative stress and telomere shortening in fibroblasts. Exp Gerontol 42(11):1039-1042

Scharf T, De Jong-Gierveld J (2008) Loneliness in urban neighbourhoods: an Aglo-Dutch comparison. Eur J Ageing 5(1):103-115

Schonknecht P, Pantel J, Kruse A, Schroder J (2005) Prevalence and natural course of aging-associated cognitive decline in a population-based sample of young-old subjects. Am J Psychiatry 162(11):2071-2077

Simon N, Smoller J, McNamara K, Maser R, Zalta A, Pollack M, Nierenberg A, Fava M, Wong K (2006) Telomere shortening and mood disorders: preliminary support for a chronic stress model of accelerated aging. Biol Psychiatry 60(5):432-435

Slagboom P, Droog S, Boomsma D (1994) Genetic determination of telomere size in humans: a twin study of three age groups. Am J Hum Genet 55(5):876-882

Taddei A, Gasser S (2004) Multiple pathways for telomere tethering: functional implications of subnuclear position for heterochromatin formation. Biochim Biophys Acta 1677(1-3):120-128

Trichopoulou A, Lagiou P (1997) Healthy traditional Mediterranean diet: an expression of culture, history, and lifestyle. Nutr Rev 55(11 Pt 1):383-389

Tyrka A, Price L, Kao H, Porton B, Marsella S, Carpenter L (2009) Childhood maltreatment and telomere shortening: preliminary support for an effect of early stress on cellular aging. Biol Psychiatry 67:531-534

Valdes A, Andrew T, Gardner J, Kimura M, Oelsner E, Cherkas L, Aviv A, Spector T (2005) Obesity, cigarette smoking, and telomere length in women. Lancet 366(9486):662-664

Valdes A, Deary I, Gardner J, Kimura M, Lu X, Spector T, Aviv A, Cherkas L (2010) Leukocyte telomere length is associated with cognitive performance in healthy women. Neurobiol Aging 31(6):986-992

Yaffe K, Lindquist K, Kluse M, Cawthon R, Harris T, Hsueh W, Simonsick E, Kuller L, Li R, Ayonayon H, Rubin S, Cummings $S$ (2009) Telomere length and cognitive function in communitydwelling elders: findings from the health $\mathrm{ABC}$ study. Neurobiol Aging 66:202-213

Yesavage J, Brink T, Rose T, Lum O, Huang V, Adey M, Leirer V (1982) Development and validation of a geriatric depression screening scale: a preliminary report. J Psychiatr Res 17(1):37-49

Zung W (1965) A self-rating depression scale. Arch Gen Psychiatry 12:63-70 